\title{
BERBAGI PENGETAHUAN SEBAGAI ALTERNATIF PENCIPTAAN PENGETAHUAN UNTUK STAF PENGAJAR VOKASI UI
}

\author{
Dyah Safitri ${ }^{1 *}$

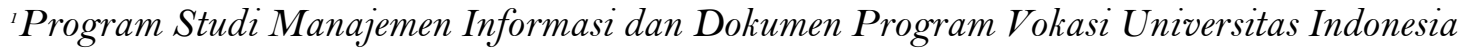

\begin{abstract}
ABSTRAK - Proses berbagi pengetahuan menjadi proses penting bagi sebuah organisasi dalam menciptakan pengetahuan dan inovasi baru. Pengetahuan yang bersifat tacit dan explicit dapat dipindahkan melalui beberapa proses berbagi pengetahuan. Budaya menjadi bagian penting dalam proses tersebut terutama penghargaan terhadap sumber pengetahuan yang bersedia membagi pengetahuannya. Pada organisasi pendidikan seperti Program Vokasi UI yang belum lama berdiri seharusnya pelembagaan penyeleksi pengetahuan seperti knowledge centre akan bermanfaat dalam proses berbagi pengetahuan.
\end{abstract}

Kata kunci: Pengetahuan, Berbagi Pengetahuan, Pengetahuan Tacit, Pengetahuan Eksplisit, Pemindahan Pengetahuan, Pengelola Pengetahuan, Pusat Pengetahuan.

ABSTRACT -The process of knowledge sharing becomes important processes for an organization in creating new knowledge and innovation. Tacit and explicit knowledge can be moved through several processes to knowledge sharing. Culture an important part of the process, especially an appreciation of the sources of knowledge that is willing to share the knowledge. In educational organizations especially recently established such as Vocational Program UI should institutionalization of knowledge as a knowledge center will be beneficial in the process of knowledge sharing.

Keywords: Knowledge, Knowledge Sharing, Tacit Knowledge, Explicit Knowledge, Knowledge Transfer, Knowledge Manager, Knowledge Center

\section{PENDAHULUAN}

\section{Latar Belakang}

Di dalam sebuah organisasi, pengetahuan adalah salah satu aset paling bernilai dan faktor penting dalam kompetisi. Siakas dan Giorgiadou (2008) berpendapat bahwa organisasi menempatkan pengetahuan sebagai faktor penting di dalam pembentukan, penggunaan, dan distribusi informasi untuk memperkuat modal pengetahuan di dalam organisasi tersebut dalam persaingan global. Kemampuan organisasi dalam belajar, beradaptasi, dan berubah menjadi kompetensi inti untuk tetap bertahan dalam persaingan. Organisasi yang sukses adalah organisasi yang berhasil menciptakan pengetahuan baru, menyebarkannya di dalam organisasi dan mendorong penciptaan produk dan layanan baru.

Tidak banyak organisasi yang mengetahui dan sadar bahwa terdapat potensi pengetahuan tersembunyi di dalam organisasi. Setiarso et.al (2008) menyatakan bahwa Delphi Group pada tahun 1997 melakukan riset tentang komposisi pengetahuan yang tersimpan pada $42 \%$ di pikiran karyawan, $26 \%$ dalam dokumen kertas, 20\% dalam 
dokumen elektronik, dan $12 \%$ dalam knowledge-base elektronik. Pengetahuan yang tersimpan di dalam pikiran anggota organisasi adalah tacit knowledge. Menurut Filos (2008) tacit knowledge bersifat personal, kombinasi antara pengalaman dan intuisi, dan tidak banyak perusahaan dapat meng-capture dan mengkomunikasikan pengetahuan tersebut. Komitmen individu di dalam organisasi menjadi faktor penentu tersebarnya tacit knowledge di dalam organisasi, sehingga perlu diciptakan kepercayaan dan loyalitas di antara individu dan organisasi. Setiarso et.al (2008) menyatakan tacit knowledge memang sangat sulit dibagi ke orang lain, dan dokumentasi menjadi faktor penting dalam mengubah tacit knowledge menjadi explicit knowledge. Tanpa dokumentasi, tacit knowledge tidak akan berarti dan menjadi sulit diakses oleh siapapun dan kapanpun di dalam organisasi.

Agar pengetahuan tetap memberi manfaat dalam jangka panjang, sebuah organisasi harus menyadari keberadaan karyawan, pencipta pengetahuan, dan penggunanya agar berbagi pengetahuan (knowledge sharing) dapat berjalan efektif dan inovasi dapat terus muncul. Menurut Saenz, Aramburu, dan Rivera (2010) penciptaan pengetahuan merupakan proses berkelanjutan dari seorang individu yang memiliki keterbatasan pengetahuan kemudian memperoleh pengetahuan baru. Dengan interaksi dan berbagi pengetahuan antar individu, individu tersebut akan memiliki pandangan dan pengetahuan baru untuk menghadapi masalah yang akan terjadi. Pada level organisasi -termasuk juga pada organisasi pendidikan- dorongan pada penciptaan pengetahuan dan inovasi pribadi akan membentuk penciptaan pengetahuan dan inovasi baru.

Sebagai salah satu organisasi pendidikan, Program Vokasi Universitas Indonesia merupakan organisasi baru yang dimulai pada 2008. Pengelolaan administasi program pendidikan vokasi dilakukan secara terpusat di Universitas Indonesia menggantikan program diploma III yang tersebar di berbagai fakultas dan sudah ada sejak tahun 1980-an. Tujuan menyatukan program tersebut adalah efisiensi mengingat banyaknya jalur pendidikan yang ada di UI serta untuk merealisasikan visi UI menjadi universitas riset kelas dunia dalam menghadapai tantangan global. Program vokasi UI merupakan kumpulan dari berbagai disiplin ilmu eksakta, sosial, ekonomi, hingga kesehatan dan kedokteran. Program pendidikan vokasi bertujuan menyiapkan peserta didik menjadi anggota masyarakat yang memiliki kemampuan tenaga ahli profesional dalam menerapkan, mengembangkan, dan menyebarluaskan teknologi dan/atau kesenian serta mengupayakan penggunaannya untuk meningkatkan taraf kehidupan masyarakat dan memperkaya kebudayaan nasional. Secara khusus, program diploma diarahkan untuk menghasilkan lulusan yang menguasai kemampuan dalam bidang kerja tertentu sehingga dapat langsung diserap sebagai tenaga kerja di industri/swasta, lembaga pemerintah atau berwiraswasta secara 
mandiri, hal ini karena beban pengajaran pada program pendidikan vokasi telah disusun lebih mengutamakan beban mata kuliah keterampilan (60\%) dibandingkan dengan beban mata kuliah teori. Visi Program Vokasi UI adalah menjadi pusat unggulan pendidikan vokasional di ASEAN. Misinya adalah Menyelenggarakan pendidikan vokasional dengan penekanan pada keahlian (skilled) dan praktek selaras dengan kebutuhan dunia kerja dan industri untuk menghasilkan tenaga ahli profesional yang berstandar internasional, mengembangkan bidang-bidang vokasional dalam upaya untuk meningkatkan taraf kehidupan dan kualitas masyarakat Indonesia, serta mengembangkan kerjasama antar lembaga/instansi di dalam dan luar negeri untuk kepentingan pendidikan, praktek kerja dan adaptasi kurikulum. (Vokasi, 2013)

Sebagai organisasi yang baru dengan membawahi pendidikan dengan lingkup rumpun ilmu yang beragam, berbagi pengetahuan untuk staf pengajar atau dosen di program vokasi UI menjadi sangat penting. Berbagai pengalaman yang diperoleh dari sebuah rumpun ilmu misalnya dapat dibagi ke dalam internal organisasi sehingga dapat dengan mudah diadaptasi oleh rumpun ilmu lainnya. Dengan budaya berbagi pengetahuan, akan lebih cepat dipetakan kekuatan program studi vokasi karena kekurangan pada program studi dapat saling terisi. Di samping itu, perkembangan ilmu dan pengayaan mata kuliah di berbagai rumpun ilmu dapat berkembang dengan lebih baik.

\section{ANALISIS DAN PEMBAHASAN}

\section{Pengetahuan}

Davenport dan Prusak (1998) menyebut pengetahuan sebagai pengalaman, nilai-nilai, konteks dan wawasan yang tercampur sehingga menyediakan sebuah kerangka kerja untuk mengevaluasi dan menghubungkan pengalaman-pengalaman dan informasi baru. Kedua peneliti itu menemukan bahwa di dalam organisasi, pengetahuan kerap menjadi artefak yang melekat seperti dokumen, video, audio atau penyimpanan di dalam rutinitas, proses, praktek, dan norma-norma organisasi. Mereka juga melihat bahwa pengetahuan akan bernilai apabila ada tambahan konteks, budaya, pengalaman, dan interpretasi dari orang lain. Nonaka (1994) melihat pengetahuan dalam arti yang lebih spesifik. Pengguna pengetahuan harus mengerti dan melihat pengalaman dengan konteks yang ada, kondisi dan pengaruh yang melingkupi, sehingga pengetahuan dihasilkan dan berarti untuk mereka.

Nonaka dan Takeuchi menggambarkan dua tipe pengetahuan yaitu pengetahuan tacit (tacitknowledge) dan pengetahuan eksplisit (explicit knowledge).

- Tacit knowledge adalah pemahaman yang ada di dalam pikiran pemilik pengetahuan dan tidak secara langsung dapat dimunculkan dalam bentuk data atau representasi pengetahuan sehingga kerap disebut pengetahuan yang tidak terstruktur. 
- Explicit knowledge yaitu pengetahuan yang secara langsung berbentuk pengetahuan dan umumnya disebut sebagai pengetahuan terstruktur. Sehingga, pengetahuan adalah gabungan antara kedua pengetahuan tersebut.

\section{Pemindahan Pengetahuan}

Nonaka dan Takeuchi menawarkan empat model pemindahan pengetahuan (knowledge transfer) sebagai model SECI (Socialization, Externalization, Combination, Internalization). Keempatnya adalah :

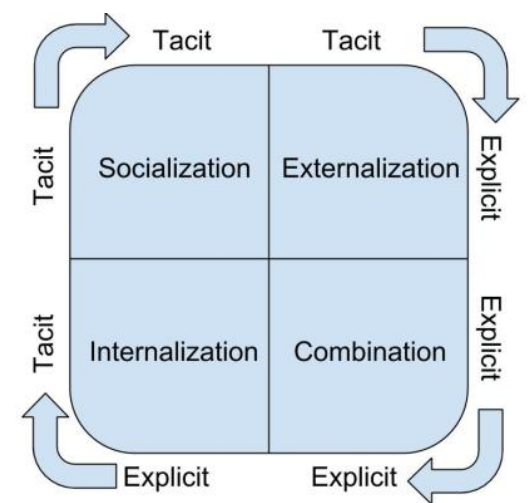

Sumber : Nonaka dan Takeuchi (1995)

Gambar 1. 1

SECI Model

- Socialization adalah proses berbagi pengetahuan dan membuat tacit knowledge sebagai model mental dan keterampilan teknis. Tacit knowledge dapat diperoleh melalui observasi, imitasi, dan praktek.

- Externalization adalah proses artikulasi tacit knowledge dalam bentuk konsep eksplisit berwujud metafora, analogis, hipotesis, atau model
- Combination adalah proses konsep sistemis ke dalam sistem pengetahuan dengan menggabungkan expilicit knowledge yang berbeda. Explicit knowledge dipindah melalui media seperti dokumen, pertemuan, email atau percakapan telepon. Kategorisasi pengetahuan ini akan memunculkan pengetahuan baru.

- Internalization adalah proses mengubah explicit knowledge menjadi tacitknowledge dan dekat dengan konsep pengalaman karena mengerjakan atau dapat disebut sebagai learning by doing

Keempat proses tersebut memperlihatkan bahwa perpindahan pengetahuan bergantung pada pemahaman antara pemilik pengetahuan dan pengguna pengetahuan. Pemahaman umum terdiri atas konteks dan pengalaman. Konteks adalah cerita di balik pengetahuan, kondisi atau situasi yang membuat pengetahuan dapat dimengerti. Sedangkan pengalaman adalah aktivitas yang memproduksi model mental bagaimana pengetahuan digunakan.

\section{Berbagai Pengetahuan}

Gupta, Sharma, Hsu (2008) berpendapat kemampuan organisasi melakukan perpindahan informasi dan pengetahuan adalah faktor penentu bagi organisasi dalam mempertahankan keunggulan kompetitifnya. Aliran informasi dan pengetahuan terjadi ketika tacit knowledgedan explicit knowledge dibedakan dalam proses pemindahannya. Transfer knowledge adalah aspek terpenting 
dari manajeman pengetahuan (knowledge management) saat pengetahuan diambil atau didapatkan dari sebuah organisasi sehingga harus dapat dibagikan dari pribadi dan kelompok di dalam organisasi tersebut.

Definisi berbagai pengetahuan datang dari Dixon (2000). Menurutnya ada lima tipe utama berbagi pengethuan yaitu serial, near, far, strategic, dan expert transfer. Masingmasing dibedakan menurut tujuan, metode, dan cara menggunakannya. Adapun lima tipe utama tersebut yaitu :

1. Serial Transfer: diterapkan ke sebuah tim yang mengerjakan satu tugas, kemudian tim yang sama mengulang tugas tersebut dalam konteks baru. Contohnya adalah tim pengganti generator uap di Bechtel (sebuah perusahaan konstruksi terkenal dari Amerika Serikat). Tim ini mengganti sebuah generator di sebuah lokasi spesifik, misalnya di perusahaan kimia, selama dua atau tiga bulan. Ketika tim menyelesaikan tugas tersebut, pekerjaan tim lantas berpindah ke kilang minyak untuk mengganti generator. Tim menggunakan kembali pengetahuan yang didapatkan dari mengerjakan perusahaan kimia. Pada serial transfer, tim sumber dan tim penerima adalah tim yang sama. Serial transfer menawarkan efisiensi dalam kecepatan dan kualitas.

2. Near transfer: melibatkan transfer pengetahuan dari tim sumber ke tim penerima yang mengerjakan pekerjaan serupa dalam konteks sama tetapi di lokasi berbeda. Syarat utamanya adalah pekerjaan tersebut merupakan pekerjaan besar dan terus menerus. Sebuah contoh adalah tim pekerja Ford di Chicago dan di Atlanta. Di Atlanta tim pekerja dapat memasang rem depan mobil baru 15 detik lebih cepat dibanding tim pekerja di Chicago. Kemudian, tim pekerja Ford di Chicago menggunakan pengetahuan tim pekerja di Atlanta untuk dapat memasang rem depan supaya mendapatkan waktu yang sama. Near transfer membawa explicit knowledge dari satu lokasi ke lokasi lainnya.

3. Far transfer : melibatkan pemindahan tacit knowledge dari tim sumber ke tim penerima ketika pengetahuan berkaitan dengan tugas non-rutin. Contohnya adalah tim ekplorasi minyak mengundang tim lain untuk membantu menginterpretasi data seismik dan geologi yang telah mereka kumpulkan. Pengetahuan ditransfer langsung ke masing-masing anggota tim terutama pada langkah dan prosedur yang tidak tertulis. Karena interpretasi dari data tersebut adalah tugas dengan beragam variabel, mereka harus menyajikan sesuai dengan pengetahuan mereka. Far transfer biasa digunakan untuk memungkinkan pemindahan pengetahuan yang sangat spesifik.

4. Strategic transfer melibatkan pemindahan pengetahuan yang sangat kompleks, seperti bagaimana merilis sebuah produk dari satu tim ke tim lain yang terpisah baik tempat maupun waktu. Transfer ini berbeda dari far transfer karena strategic transfer lebih terbatas lingkupnya seperti pada satu tim tertentu. Biasanya strategic transfer akan bermanfaat bagi perusahaan 
berskala global ketika pengetahuan bisa dipindahkan ke lokasi cabang di belahan dunia lain dengan konteks lingkungan yang berbeda.

5. Expert Transfer, melibatkan pemindahan explicit knowledge mengenai tugas yang dikerjakan rutin. Contohnya adalah teknisi yang mengirim surat elektronik ke jaringan pertemanannya untuk bertanya bagaimana meningkatkan kecerahan monitor kuno dan mendapatkan jawaban dari ahli yang mendalami bidang tersebut.
Di dalam model transfer ini, kebutuhan keahlian dapat menjawab berbagai pertanyaan yang diajukan.

Jacobson (2008) menekankan bahwa dalam memahami berbagi pengetahuan harus mengerti apa yang terjadi di level individu sebagai pusat dari proses tersebut. Jacobsonmenawarkan model knowledge sharing yang diadaptasi dari model proses komunikasi Shannon Weaver dan Barlo. Model yang ditawarkan oleh Jacobson adalah sebagai berikut:

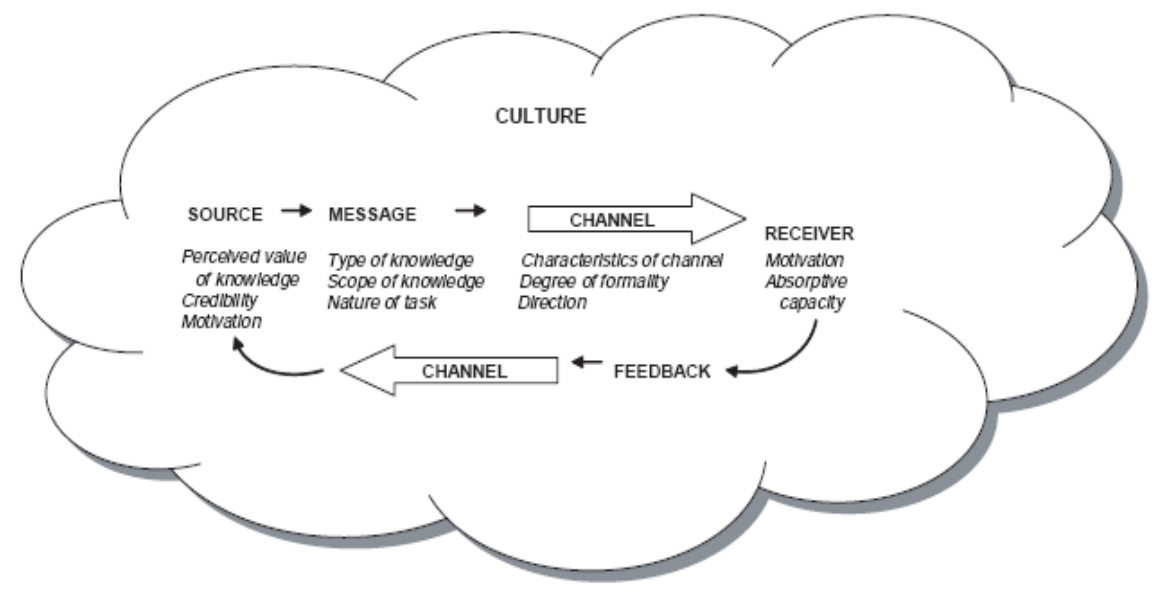

Sumber : Jacobson (2008)

Gambar 1.2

Model knowledge sharing Jacobson

Ada enam faktor utama yang dapat dilihat dalam proses berbagi pengetahuan

1. Sumber pengetahuan yaitu individu yang memiliki pengetahuan dan memindahkan pengetahuan tersebut ke orang lain. Ada tiga karakteristik sumber pengetahuan yaitu :

a. Aliran pengetahuan antar individu diasosiasikan dengan biaya, maka pemilik pengetahuan dianggap lebih bernilai dibanding yang tidak memiliki.

b. Kredibilitas sumber pengetahuan, ini berhubungan dengan kompetensi seseorang untuk membagi pengetahuan yang dimilikinya.

c. Motivasi dari sumber pengetahuan untuk bersedia berbagi karena yang memiliki pengetahuan biasanya 
memiliki status kekuasan lebih besar di organisasi.

2. Pesan. Jacobson melihat bahwa jenis pengetahuan dan cakupan pengetahuan seperti apa yang akan dibagi dalam organisasi.

3. Penerima pengetahuan. Pada proses berbagi pengetahuan, efektivitasnya bergantung pada motivasi dan kapasitas menyerap dari penerima pengetahuan. Motivasi lebih pada persoalan pemahaman menggunakan pengetahuan dari sumber lain. Sedangkan kapasitas menyerap pengetahuan baru adalah bagaimana pengetahuan tersebut dapat digabungkan dengan pengetahuan yang dimiliki.

4. Kanal komunikasi atau bagaimana pengetahuan dikomunikasikan. Ada sejumlah kanal yang dapat digunakan untuk berbagi pengetahuan mulai dari pertemuan tatap muka langsung, hingga menggunakan jalur teknologi informasi (internet, email, forum diskusi, hingga portal berbagi pengetahuan). Kanal komunikasi ini bisa bersifat formal dan non-formal.

5. Umpan balik. Berbagi pengetahuan dapat terlihat apabila ada respon verbal maupun non-verbal dari penerima pengetahuan yang menandakan penerima mengerti pesan yang diterima.

6. Budaya organisasi. Budaya yang direfleksikan ke dalam nilai-nilai organisasi, norma-norma, dan dipraktekkan dalam kegiatan sehari-hari di sebuah organisasi. Ada empat aspek yang dapat dilihat bagaimana budaya dapat memengaruhi knowledge sharing, yaitu :

a. Ukuran asumsi budaya yang melihat pengetahuan sebagai sesuatu yang penting

b. Budaya menjadi mediasi di antara pengetahuan individu, kelompok, dan organisasi

c. Budaya menciptakan konteks organisasi dalam interaksi sosial

d. Budaya berdampak pada penciptaan dan adopsi pengetahuan baru.

Satu nilai yang disebutkan oleh Jacobson sebagai bagian budaya berbagi pengetahuan adalah kepercayaan, yakni ada penghormatan kepada pemilik ide. Hal ini diharapkan agar dalam proses berbagi pengetahuan, orang yang memberi pengetahuan baru harus mendapat penghargaan dan balasan setara. Kepercayaan harus transparan atau dapat dilihat dimana-mana dan harus dimulai dari jajaran manajemen teratas. Secara khusus, manajemen teratas harus melakukan hal tersebut karena kegiatan mereka didefinisikan sebagai nilai-nilai dalam organisasi.

Untuk proses berbagi pengetahuan untuk staf pengajar di Program Vokasi UI sebagai alternatif penciptaan pengetahuan, model Jacobson dan Dixon dapat diadaptasi dalam pelaksanaan. Penulis menawarkan model pengembangan sebagai berikut : 


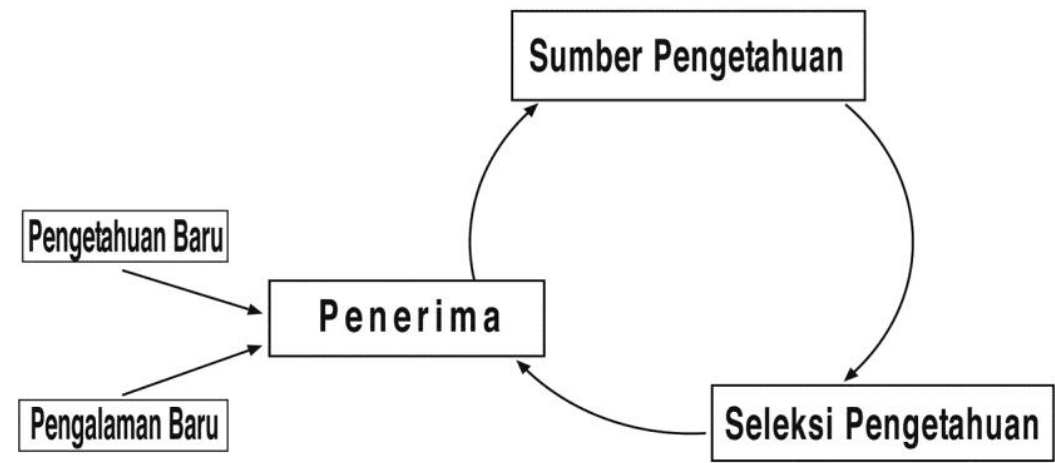

Gambar 1.3

Model Berbagi Pengetahuan Untuk Staf Pengajar di Program Vokasi UI

Proses ini terbentuk dalam siklus yang berulang. Sumber pengetahuan dapat berupa pengetahuan staf pengajar Vokasi UI yang bersifat tacit dan explicit. Pada tingkatan rumpun program studi, pengetahuan tacit dan eksplisit dapat dialirkan kepada penerima menjadi pengetahuan baru bagi program studi lainnya di lingkungan Program Vokasi UI.

Pada tahapan seleksi pengetahuan perlu ada lembaga yang dapat memilah dan memilih pengetahuan apa saja yang dapat dialirkan ke dalam organisasi. Lembaga ini dapat berupa perorangan yang ditunjuk untuk mengelola aktivitas berbagi pengetahuan seperti manajer pengetahuan (knowledge manager). Lembaga ini juga dapat menjadi bagian dari organisasi dan diberi fungsi dan wewenang melakukan seleksi pengetahan yang akan dialirkan. Lembaga penyeleksi ini berperan penting apakah nantinya pengetahuan tersebut dapat dipindahkan melalui metode yang tepat apakah menggunakan pendekatan near, serial, far, strategic ataupun expert transfer saat mengalirkan pengetahuan. Pemakaian media apa saja dalam membagi pengetahuan baru juga menjadi tanggung jawab dari lembaga penyeleksi ini. Lembaga yang menjadi bagian dari struktur organisasi dapat berupa pusat pengetahuan (knowledge center) yang dikelola profesional.

Pada penerima pengetahuan, dapat diartikan sebagai staf pengajar sebagai profesional maupun lembaga yaitu berbagai program studi di Program Vokasi UI. Penerima akan menerima pengetahuan baru yang mengalir dari penyeleksi pengetahuan. Selanjutnya mereka akan memberi makna dan pengalaman baru pada pengetahuan tersebut. Setelah memberi makna dan pengalaman baru pada pengetahuan yang telah dialirkan oleh lembaga penyeleksi maka pengetahuan baru akan terbentuk. Proses ini berlaku terus menerus dan membentuk siklus yang tidak terhenti sehingga proses berbagi pengetahuan akan menjadi bagian tak terpisahkan dari jalannya organisasi.

\section{KESIMPULAN}

Berbagi pengetahuan adalah proses penting di dalam sebuah organisasi dalam mengelola dan menciptakan pengetahuan 
baru. Pada organisasi baru seperti pada Program Vokasi UI, penting untuk mengelola pengetahuan sejak dini. Pelembagaan berbagi pengetahuan seperti melalui orang yang bertanggung jawab pada mengalirnya pengetahuan (knowledge manager) maupun yang berbentuk dalam struktur organisasi seperti pusat pengetahuan (knowledge center) menjadi demikian penting agar penciptaan pengetahuan baru dapat berlangsung mudah dan terus menerus. Penambahan pengetahuan dan pengalaman baru yang dimiliki oleh staf pengajar sebagai profesional maupun rumpun program studi nantinya akan membentuk pengetahuan baru yang nanti akan terus dialirkan ke semua staf pengajar maupun rumpun program studi lainnya.

Proses berbagi pengetahuan adalah proses terus menerus dan berlangsung melekat dengan berlangsungnya organisasi. Organisasi dapat memanfaatkan pengetahuan yang berlimpah seperti pengetahuan di organisasi pendidikan. Setelah melalui proses siklus tersebut, organisasi pendidikan tentu akan memperoleh manfaat dari proses berbagi pengetahuan tersebut apabila prosesnya berjalan lancar dan terlembagakan.

\section{DAFTAR PUSTAKA}

Davenport, T. H. \& Prusak, L. (1998). Working Knowledge: How Organizations Manage What They Know. Boston : Harvard Business School Press.

Dixon, N. M. (2000). Common Knowledge: How Companies Thrive by Sharing What They Know. Boston: Harvard Business School Press.

Filos, Erastos (2008). Smart Organization in The Digital Age. In Jennex, Murray E. (Ed). Knowledge Management : Concept, Methodologies, Tools, and Application. (vol. 1, pp.48-72). Hershey : Information Science Reference.

Gupta,J., Sharma,SK.,Hsu, J. (2008). An Overview of Knowledge Management. In Jennex, Murray E (Ed). Knowledge Management : Concept, Methodologies, Tools, and Application. (vol. 1, pp. 1-22). Hershey : Information Science Reference.

Jacobson, Carolyn (2008) Knowledge Sharing Between Individual. In Jennex, Murray E. (Ed). Knowledge Management : Concept, Methodologies, Tools, And Application. (vol. 3. pp 1633-1641). Hershey : Information Science Reference

Nonaka, I. \& Takeuchi, H. (1995). The Knowledge-Creating Company: How Japanese Companies Create the Dynamics Innovation New York: Oxford University Press.

Saenz, J.,Aramburu,N.,Rivera,O. (2010) Exploring the Links between Structural Capital, Knowledge Sharing, Innovation Capability, and Business Competitiveness : An Empirical Study. In Harorimana, Deogratius (Ed). Cultural Implications of Knowledge Sharing, Management and Transfer.(pp.32 1-354). Pennsylvania : Information Science Reference.

Setiarso, Bambang., et.al (2009). Penerapan Knowledge Manajemen Pada Organisasi. Yogyakarta : Graha Ilmu. 
Siakas, Kerstin dan Georgiadou, Elli (2008). Knowledge Sharing in Virtual and Networked Organisations in Different Organisational and National Cultures. In Bolisani, Ettore (Ed) Building The Knowledge Society in The Internet. Sharing and Exchanging Knowledge in Networked Environments (pp 45- 64).Hersey : Information Science Reference.

Tentang Program Vokasi.http://vokasi.ui.ac.id/web/?page id=414 [15 November 2013] 